\title{
Protracted otitis media with effusion in an adult patient with adenoid vegetation. Clinical case presentation
}

\author{
Dr. Konstantin Borisov \\ ENT clinic at University First MHAT-Sofia EAD \\ Under the leadership of Prof. Veselin Pavlov MD
}

\begin{abstract}
Background

Otitis media with effusion (OME) is characterized by the accumulation of non-purulent discharge in the middle ear cavity, with no signs or symptoms of acute ear infection. If the effusion persists for 3 months or more, this is considered a case of chronic otitis media with effusion (COME). The main pathogenetic mechanism for the occurrence of serous otitis is the dilatory dysfunction of the Eustachian tube. This dysfunction can be due to a number of reasons, the main one being an external obstruction resulting from the constriction of the opening of the Eustachian tube by adenoid vegetation or tumors. We present a case of protracted otitis media with effusion and adenoid vegetation in a 24-year-old man- with bilateral combined hearing loss, upper airway obstruction, and chronic sinuitis- successfully treated by bilateral tympanostomy and adenoidectomy.

Materials and methods

In our clinical case we have described chronologically the investigations and chosen tactics of treatment, applied to our patient, some immediate results, but also the long-term consequences of the management of this disease.

Results

In our opinion, the outcomes in this patient's case were prompted not only by the specifics of this disease, but also by the interpretation of the instrumental examination and the decision-making regarding the initial treatment.
\end{abstract}

\section{Introduction}

Otitis media with effusion (OME) and adenoid vegetation are among the most common diagnoses in pediatric otorhinolaryngology. Adenoid vegetation is most common in children between 3 and 7 years of age. The pharyngeal tonsil, as part of the Waldayer lymphatic ring, undergoes physiological growth until the age of 6 , atrophies during puberty and almost completely disappears around the twenties. In adults, it is rare and hardly unusual to diagnose a case of adenoid vegetation. About $90 \%$ of children under the age of 10 have at least once been diagnosed with otitis media with effusion, with the disease most often occurring between the ages of 2 and 4. Although it is significantly less common, otitis media with effusion can also develop in adults, in patients with sinuitis, allergic rhinitis, tumors in the epipharynx, and when sudden changes in pressure occur (flying or diving).

\section{Clinical Case}

\subsection{Factology}

The patient is a 24-year-old man, non-smoker, with a concomitant disease- bilateral neurosensory hearing loss (diagnosed about three years ago). He was admitted to the clinic for diagnostic clarification and treatment, complaining from muffled hearing and pain in the ears, severely obstructed nasal breathing, heaviness in the facial area and purulent drainage on the posterior pharyngeal wall. During the detailed history taking, the patient reported obstructed nasal breathing, nasal speech, frequent 
sinuitis, otitis, slip apnea syndrome, and frequent inflammation of the upper respiratory tract since childhood. He had been treated repeatedly with antibiotics, nasal drops, antihistamines, punctures of the maxillary sinuses- with slight improvement and new relapses. Physical examination: Blood pressure 130/80 mm Hg, pulse 74 beats/minute, body temperature $36.7^{\circ} \mathrm{C}$. Erythrocyte sedimentation rate $20 \mathrm{~mm} / \mathrm{H}$. The rest of the paraclinic is normal. Chest radiography: expanded and enlightened lung fields. No evidence of an active pulmonary process. Cardiovascular shadow- within the age norm. The objective examination revealed bilaterally infiltrated, pinkish-yellow bulging tympanic membranes; a pale pink tumor formation with a granular structure located on the posterior epipharyngeal wall, reaching the torus tubarium bilaterally; tonal threshold audiometry- bilateral combined hearing reduction.

A contrast-enhanced CT scan of the epipharynx and neck provided evidence of a tumor formation in the epipharynx, obstructing the nasal choanae without evidence of infiltration. Cervical lymphadenomegaly.

\subsection{Medical treatment}

A working diagnosis of protracted otitis with effusion and adenoid vegetation was suggested, possible juvenile nasopharyngeal angiofibroma. After consulting a cardiologist and an anesthesiologist, a дясно ухо

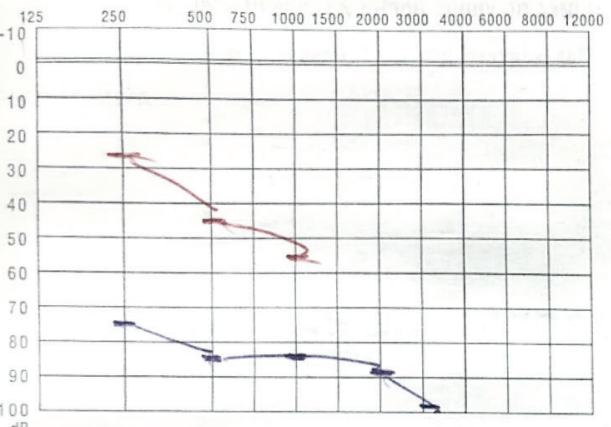

ляво ухо

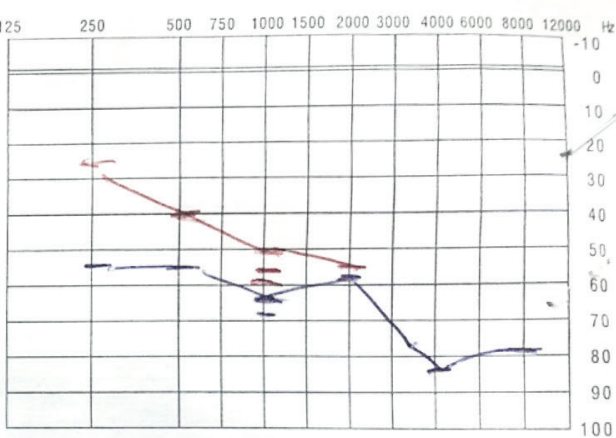

Fig. 1. Tonal threshold audiometry. Left ear attenuation $90 \mathrm{Db}$.

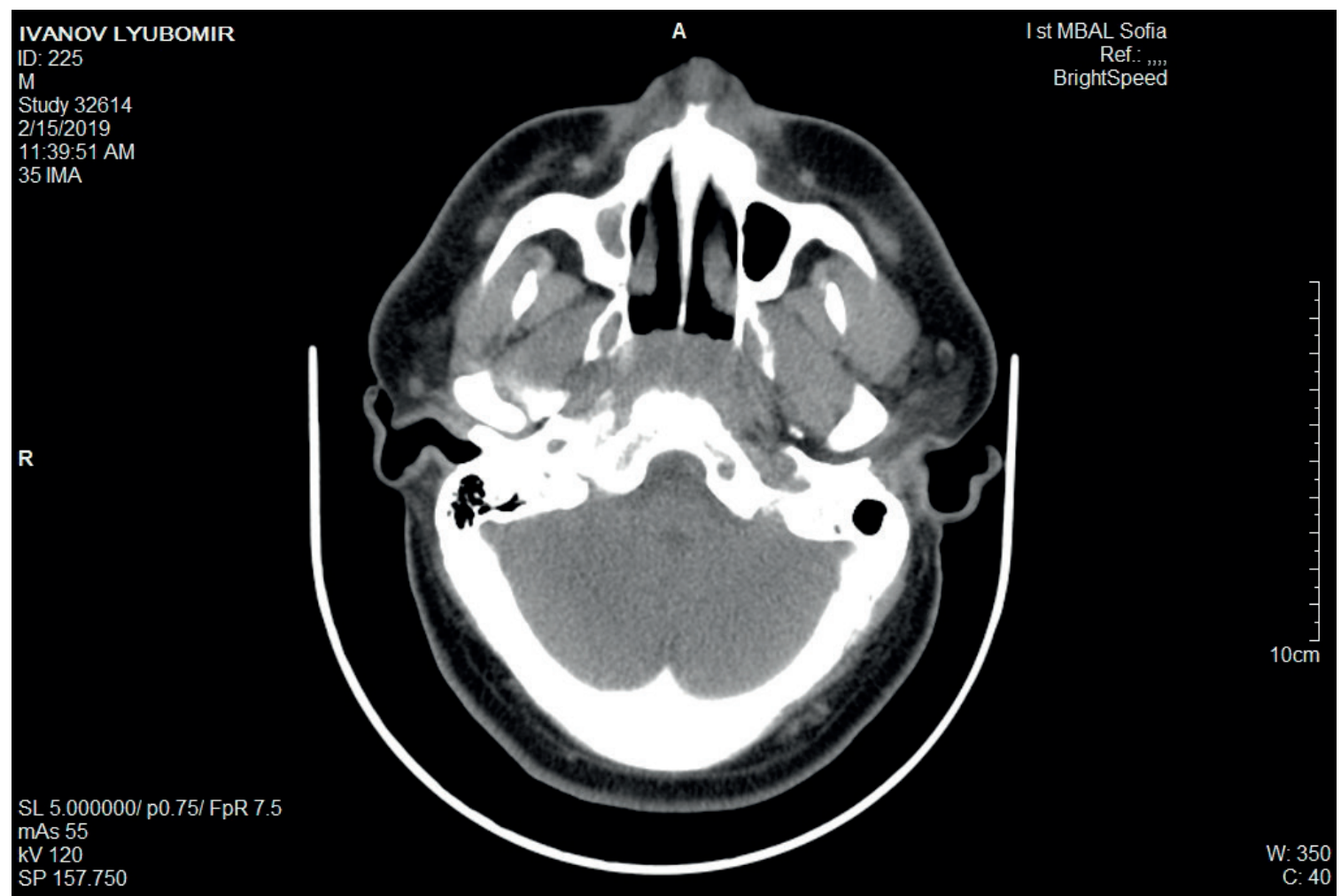

Fig. 2. CAT of the epipharynx with adenoid hypertrophy filling the epipharynx and choanae 
myingotomy of the right tympanic membrane was performed under general anesthesia, a serous secretion was aspirated (intraoperatively it was decided not to apply a Teflon tube) and material was taken from the tumor formation located in the epipharynx. Histological finding: epithelium and underlying hyperplasia of the lymph tissue.

After a smooth postoperative period, the patient was discharged from the clinic with a scheduled adenoidectomy. About a month after the first hospitalization, a planned surgical treatment was undertaken- adenoidectomy under general anesthesia. A large adenoid vegetation was removed transorally, through curettage. The postoperative period went smoothly and without complications. Ten days after the operation, the feeling of fullness in the ears and the obstructed nasal breathing disappeared. To date no further progress has ever been marked in the person's record at the outpatient clinic.

\section{Discussion}

The pharyngeal tonsil is a lymph tissue located in the posterior-upper region of the nasopharynx. It is part of the first line of immunological defense mechanisms of the upper respiratory tract and reaches its maximum size between 3 and 7 years of age. Its atrophy usually begins around the age of 10 and ends around the age of 20. However, in clinical practice, adenoid vegetation can also occur in adults. The most common complaints include difficulty in nasal breathing, nasal speech, frequent sinuitis, otitis media with conductive hearing loss, sleep apnea syndrome, cephalgia and frequent inflammation of the upper respiratory tract. The diagnosis is based on the taken medical history and the findings of nasal endoscopy, posterior rhinoscopy, radiography of the nasal cavities and the epipharynx. Differential diagnostic problems associated with benign or malignant lesions of the epipharynx should be addressed with a contrast-enhanced CAT and a subsequent surgical treatment, followed by a histological diagnosis.

The main pathogenetic mechanism for the development of otitis with effusion in patients with adenoid vegetation is Eustachian tube dysfunction. Pure mechanical compression of the tube by hypertrophied adenoid vegetation is rare and it is now acknowledged that what connects the latter and otitis with effusion is the transmission of a neighboring infec- tion. Presumably, OME is a non-infectious disease. However, retrothympanic secretions are not always sterile. In approximately $50 \%$ of cases, the presence of Streptococcus pneumonia, Haemophilus influenza or Moraxella catarrhalis is detected in the ear canal. In patients with persistent tubal dysfunction for more than one month, as a result of the reduced oxygen content in the middle ear, the cylindrical nasal epithelium is replaced by squamous, the number of mucous cells and glands increases, and the effusion becomes more viscous. Otitis with effusion is diagnosed by otoscopy under a microscope, tonal threshold audiometry and tympanometry. The tonal threshold audiometry shows conductive hearing loss with normal bone conduction and a horizontal air permeability curve at the level of 20 to 40 decibels. When the windows are blocked by a viscous effusion or as an expression of a toxic damage to the inner ear, a decrease in air and bone conductivity at high frequencies can be observed.

A number of medical, surgical and physical methods are taken into consideration in the treatment of OME in adult patients with adenoid vegetation. The drug treatment includes nasal decongestants, antihistamines, calcium supplements, mucolytics, topical washes with alkaline solutions, topical corticosteroids, and antibiotics. Surgical methods include adenotomy (should be considered as a mandatory method), myringotomy and tympanostomy with application of a tube into the tympanic membrane. The physical treatment for serous otitis with effusion includes Politzer purge, middle ear physiotherapy, and pressure chamber treatment.

\section{Conclusions}

The relatively simple diagnostics with modern diagnostic methods and the abundance of options for surgical treatment or even combined therapy in complex cases, do not pose difficulties in the treatment of protracted otitis media with effusion in adult patients with adenoid vegetation. Although adenoid vegetation is rare in adults, in protracted serous otitis and in long-term nasal and obstructive symptoms unresponsive to conservative treatment, a thorough examination of the epipharynx is necessary. Differential diagnostic problems associated with benign or malignant lesions of the epipharynx should be addressed using contrast-enhanced CAT. Surgical treatment is optional. 


\section{References}

1. Yildirim, N., Şahan, M., Karslioğlu, Y. Adenoid hypertrophy in adults: Clinical and morphological characteristics. Journal of International Medical Research 36 (1), pp. 157-162.

2. Ishwar Singh, Avani Jain, Purodha Prasad, Pragya Rajpurohit, Adenoid hypertrophy I adults: An inderdiagnosed entity? Arch Otolaryngol Rhinol 3(1).

3. Пл. Недев, Г. Илиев, К. Керимов, М. Милков, Б. Банова Аденоидна вегетация при възрастни. Представяне на случай. Международен бюлетин по оториноларингология брой 4/2010.

4. Babu A.R., T.S. Shetty, Bharathi M.B., Parijat Joshi, Evaluation and Management of Adult Patients with Bilateral Nasal Obstruction Secondary to Adenoid Hypertrophy using Endoscopic Adenoidectomy. International Journal of Contemporary Medical Research Volume 3, Issue 6, June 2016.

5. Kieserman SP, Stern J: Malignant transformation of nasopharyngeal lymphoid hyperplasia. Otolaryngol Head Neck Surg. $1995 ; 113: 474-476$.

Reviewer of the article: Assoc. prof. Dr. Petar Rouev, MD, PhD - Trakya Hospital

\section{Correspondence to:}

dr_konstantin_borisov@abv.bg 